\title{
Combinação entre turfa vermelha e areia na obtenção de substrato-inóculo do fungo micorrízico arbuscular Glomus clarum
}

\author{
Combination of red peat and sand for obtaining substrate-inoculum of arbuscular mycorrhizal fungi \\ Glomus clarum
}

\author{
Samar Velho da Silveira ${ }^{*}$ Flávio Bello Fialho ${ }^{\mathrm{I}}$ Sérgio Francisco Schwarz ${ }^{\mathrm{II}}$ \\ Paulo Vitor Dutra de Souza ${ }^{\text {II }}$
}

\section{RESUMO}

\begin{abstract}
O objetivo com o presente estudo foi verificar a influência de diferentes proporções de turfa vermelha e areia na composição do substrato sobre a colonização radicular por fungos micorríozicos arbusculares (FMA) e no desenvolvimento vegetativo de aveia branca. O experimento foi conduzido em casa de vegetação e os tratamentos foram constituídos a partir de combinações de turfa vermelha $(T) e$ areia (A): $100 \%$ A; $25 \% T+75 \%$ A; $50 \% T+50 \%$; $75 \% T+25 \%$; $100 \%$ T. Dez sementes de aveia foram semeadas por vaso plástico preto $(350 \mathrm{ml}$ de volume), contendo 5 gramas de inóculo de Glomus clarum. Quarenta e três dias após a semeadura da aveia, foram realizadas avaliações de desenvolvimento vegetativo e colonização micorrízica do sistema radicular das plantas, através da presença de estruturas, como hifas, arbúsculos e vesículas. Substratos com maior quantidade de turfa induziram maior desenvolvimento da parte aérea e maior qualidade de raízes $(Q R)$, em termos de volume de raízes. Entretanto, a presença da turfa acima de $50 \%$ no substrato diminuiu a percentagem de colonização micorrízica da aveia. A similaridade verificada entre as curvas de regressões de percentagem de colonização e Água Facilmente Disponível, com mesmo ponto de máximo, sugerem que a quantidade de mesoporos resultante da combinação turfalareia influencia na resposta dos FMA, a melhor resposta é obtida em mistura com $32,5 \%$ de turfa vermelha.
\end{abstract}

Palavras-chave: endomicorrizas, características físicas do substrato, produção de inóculo.

\section{ABSTRACT}

The purpose of this study was to investigate the influence of different proportions of red peat and sand in the substrate on root colonization by arbuscular mycorrhizal fungi $(A M F)$ and the consequent growth of white oats. The experiment was conducted in a greenhouse and the treatments consisted of combinations of read peat $(T)$ and sand $(A)$ : 100\%A; $25 \% T+75 \%$ A $; 50 \% T+50 \% A ; 75 \% T+25 \%$ A $; 100 \% T$. Ten oat seeds were sown per container $(350 \mathrm{ml}$ volume) containing 5 grams of Glomus clarum inoculum. Forty-three days after sowing, vegetative development and mycorrhizae colonization of the plants' root system were evaluated by recording the presence of structures such as hyphae, arbuscules and vesicles. Substrates with higher amount of red peat led to increased shoot growth and quality of roots. However, the presence of peat above $50 \%$ in the substrate decreased the percentage of colonization of oats by AMF. The similarity of the regression curves of percentage of colonization and readily available water, with the same maximum point, suggest that the amount of mesopores influences the AMF response. It is concluded that the best quality of the substrate for the production of inoculum of Glomus clarum in mixtures of red peat and sand is obtained with about $32,5 \%$ red peat content in the mixture.

Key words: endomycorrhizae, physical characteristics of the substrate, inoculum production.

\section{INTRODUÇÃO}

A inoculação de fungos micorrízicos arbusculares em plantas de diversas espécies de interesse econômico vem aumentando nos últimos anos, devido às várias possibilidades de utilização deste simbionte na agricultura (AZCÓN et al., 2009). Dentro desse contexto, o substrato assume grande importância,

'Embrapa Uva e Vinho, Rua Livramento, 515, 95700-000, Bento Gonçalves, RS, Brasil. E-mail: samar@ cnpuv.embrapa.br. *Autor para correspondência.

"Departamendo de Horticultura e Silvicultura, Universidade Federal do Rio Grande do Sul (UFRGS), Porto Alegre, RS, Brasil. 
pois suas características químicas e físicas influenciam de maneira direta na colonização das plantas por fungos micorrízicos arbusculares (FMA) (ZENKE et al., 2003).

Nesse sentido, o uso de um componente de característica acentuadamente orgânica é importante na composição do substrato, pois pode ser utilizado na combinação com materiais minerais para melhorar propriedades físicas, como a aeração e a retenção de água (KÄMPF, 2000), além das características químicas. Apesar de escassos, alguns estudos têm evidenciado a influência da matéria orgânica na colonização das raízes das plantas por FMA. Dessa forma, ZAMBOLIM \& COSTA (1992) observaram o favorecimento da esporulação de FMA (70,42 clamidosporos $\mathrm{cm}^{-3}$ de substato) pela adição de turfa e esterco de galinha curtido. MINHONI et al. (1993), no entanto, observaram diminuição na esporulação de FMA (24,5 esporos 100g substrato $^{-1}$ ) pela adição de bagaço de cana.

Como os FMA são simbiontes obrigatórios, normalmente utilizam-se plantas de ciclo rápido, como aveia branca (Avena sativa), trevo (Trifolium sp.), dentre outras, para produção de inóculo. Nesse sentido, o objetivo com este trabalho foi verificar o efeito de diferentes proporções de turfa vermelha e areia na obtenção do substrato-inóculo do fungo micorrízico arbuscular Glomus clarum Nicol. \& Schenck, avaliado sob cultivo da aveia branca (Avena sativa).

\section{MATERIAL E MÉTODOS}

O experimento foi conduzido em casa de vegetação no Depto. de Horticultura e Silvicultura da Faculdade de Agronomia, UFRGS, Porto Alegre, RS.

Ambos materiais (turfa vermelha e areia) foram caracterizados química ( $\mathrm{pH}, \%$ carbono orgânico (CO), teor total de sais solúveis (TTSS), macro e micronutrientes) e fisicamente (densidade seca (DS), densidade úmida (DU), porosidade total (PT), espaço de aeração (EA), água facilmente disponível (AFD), água disponível (AD), água tamponante (AT), água remanescente à pressão de sucção de $100 \mathrm{hPa}(\mathrm{AR}$ 100) (Tabela 1).

Tabela 1 - Densidade úmida (DU), Densidade Seca (DS), Porosidade Total (PT), Espaço de Aeração (EA), Água Facilmente Disponível (AFD), Água Disponível (AD), Água Tamponante (AT), Água Remanescente (AR-100), pH, Teor Total de Sais Solúveis (TTSS), Carbono Orgânico (C.O., \%) e minerais dos diferentes substratos (T1 - 100\% Areia; T2 - 25\% Turfa vermelha + 75\% Areia; T3 $50 \%$ Turfa vermelha $+50 \%$ Areia; T $-75 \%$ Turfa vermelha $+25 \%$ Areia; T5 - 100\% Turfa vermelha), antes do cultivo com aveia branca. Porto Alegre, Faculdade de Agronomia, UFRGS, 2002.

\begin{tabular}{|c|c|c|c|c|c|c|}
\hline Tratamentos & $\mathrm{T} 1$ & $\mathrm{~T} 2$ & $\mathrm{~T} 3$ & $\mathrm{~T} 4$ & $\mathrm{~T} 5$ & Valores ideais * \\
\hline $\mathrm{DU}\left(\mathrm{kg} \mathrm{m}^{-3}\right)$ & 1474,7 & 1263,3 & 1079,1 & 762,9 & 515,2 & - \\
\hline $\mathrm{DS}\left(\mathrm{kg} \mathrm{m}^{-3}\right)$ & 1436,2 & 1164,8 & 915,6 & 525,9 & 213 & $400-500$ \\
\hline PT $\left(\mathrm{m}^{3} \mathrm{~m}^{-3}\right)$ & 0,40 & 0,51 & 0,53 & 0,76 & 0,88 & 0,85 \\
\hline $\mathrm{EA}\left(\mathrm{m}^{3} \mathrm{~m}^{-3}\right)$ & 0,07 & 0,09 & 0,11 & 0,15 & 0,21 & 0,3 \\
\hline $\operatorname{AFD}\left(\mathrm{m}^{3} \mathrm{~m}^{-3}\right)$ & 0,23 & 0,29 & 0,29 & 0,27 & 0,25 & $20-30$ \\
\hline $\operatorname{AD}\left(\mathrm{m}^{3} \mathrm{~m}^{-3}\right)$ & 0,29 & 0,30 & 0,32 & 0,32 & 0,30 & $24-40$ \\
\hline $\operatorname{AT}\left(\mathrm{m}^{3} \mathrm{~m}^{-3}\right)$ & 0,01 & 0,01 & 0,03 & 0,04 & 0,05 & 0,05 \\
\hline AR-100 $\left(\mathrm{m}^{3} \mathrm{~m}^{-3}\right)$ & 0,04 & 0,12 & 0,21 & 0,29 & 0,37 & $0,25-30$ \\
\hline $\mathrm{pH}(\mathrm{H} 2 \mathrm{O})$ & 6,6 & 6,5 & 6,3 & 6,1 & 6,0 & $5,5-6,0$ \\
\hline $\operatorname{TTSS}\left(\mathrm{g} \mathrm{L}^{-1}\right)$ & 0,21 & 0,25 & 0,34 & 0,49 & 0,71 & $0,5-1,0$ \\
\hline C.O. $(\%)$ & - & 2,4 & 8,0 & 14 & 32 & 25 \\
\hline $\mathrm{P}\left(\mathrm{mg} \mathrm{kg}^{-1}\right)$ & - & 8,9 & 12 & 13 & 17 & - \\
\hline $\mathrm{K}\left(\mathrm{mg} \mathrm{kg}^{-1}\right)$ & - & 26 & 31 & 38 & 52 & - \\
\hline $\mathrm{Al}\left(\mathrm{cmolc} \mathrm{kg}^{-1}\right)$ & - & 0 & 0,0 & 0,0 & 0,0 & - \\
\hline $\mathrm{Ca}\left(\mathrm{cmolc} \mathrm{kg}^{-1}\right)$ & - & 3 & 10 & 16 & 49 & - \\
\hline $\operatorname{Mg}\left(\mathrm{cmolc} \mathrm{kg}^{-1}\right)$ & - & 1 & 2,4 & 3,8 & 10 & - \\
\hline $\mathrm{S}\left(\mathrm{mg} \mathrm{kg}^{-1}\right)$ & - & 15 & 29 & 14 & 37 & - \\
\hline $\mathrm{Zn}\left(\mathrm{mg} \mathrm{kg}^{-1}\right)$ & - & 2,2 & 2,8 & 2,9 & 2,0 & - \\
\hline $\mathrm{Cu}\left(\mathrm{mg} \mathrm{kg}^{-1}\right)$ & - & 0,4 & 0,2 & 0,1 & 0,2 & - \\
\hline $\mathrm{B}\left(\mathrm{mg} \mathrm{kg}^{-1}\right)$ & - & 1,0 & 1,0 & 1,0 & 1,0 & - \\
\hline $\operatorname{Mn}\left(\mathrm{mg} \mathrm{kg}^{-1}\right)$ & - & 8 & 12 & 13 & 13 & - \\
\hline
\end{tabular}

*Refere-se aos valores ideais para o desenvolvimento das plantas. 
Os valores de $\mathrm{pH}\left(\mathrm{H}_{2} \mathrm{O}\right)$ dos materiais foram determinados através de potenciômetro, em suspensões substrato:água deionizada na proporção de 1:2,5 (volume:volume), seguindo método empregado pela VDLUFA (União das entidades Alemãs de Pesquisas Agrícolas) para substratos hortícolas (HOFFMANN, 1970). O pH da turfa foi corrigido para pH 6,0 através da adição de $8 \mathrm{~g} \mathrm{CaCO}_{3} \mathrm{~L}^{-1}$ de substrato, de acordo com curva de calibração realizada anteriormente, conforme metodologia descrita por BELLÉ(1990).

O teor de TTSS das amostras foi determinado através de condutivímetro, em suspensão substrato:água deionizada na proporção de 1:10 (peso:volume), em função da condutividade elétrica do extrato, expressa como teor de $\mathrm{KCl}$ (RÖBER \& SCHALLER, 1985).

A determinação do teor de $\mathrm{CO}$ da turfa foi realizada pelo Laboratório de Análises de Solos e Tecidos da Faculdade de Agronomia (UFRGS), feita pelo método Walkley-Black com calor externo (SCHUMACHER, 2002).

A DS foi calculada seguindo o método descrito por HOFFMAN (1970). Para determinação da PT, EA, AFD, AD, AT, AR-100, os materiais componentes foram caracterizados quanto às suas relações água:ar em diferentes condições de umidade, seguindo a metodologia proposta por DE BOODT \& VERDOCK (1972). Os teores percentuais de volume de água contido nos materiais foram determinados a partir de sucção referente aos pontos de tensão $0,10,50$ e $100 \mathrm{~cm}$ de altura da coluna de água (equivalentes às sucções de 0, 10, 50 e 100hPa), estabelecida em funil de tensão do Laboratório de Substratos do Departamento de Horticultura e Silvicultura da Faculdade de Agronomia da UFRGS.

Sementes de aveia foram semeadas em vasos plásticos pretos (350ml de volume), preenchidos com diferentes combinações de areia e turfa vermelha. Tanto a areia quanto a turfa foram previamente desinfestados em autoclave, a $120^{\circ} \mathrm{C}$, por uma hora, sendo essa operação repetida por três vezes, entre períodos de 24 horas.

O delineamento experimental utilizado foi o de blocos casualizados. Cinco tratamentos foram gerados a partir da mistura de turfa vermelha e areia, com base em volume:volume, na umidade de trabalho: $100 \%$ Areia; $25 \%$ Turfa vermelha $+75 \%$ Areia; $50 \%$ Turfa vermelha $+50 \%$ Areia; $75 \%$ Turfa vermelha + $25 \%$ Areia; $100 \%$ Turfa vermelha.

Amostras dos substratos dos diferentes tratamentos foram encaminhadas ao Laboratório de Análise de Solos e Tecidos da Faculdade de Agronomia da UFRGS para realização das análises de Macro e Micronutrientes, segundo metodologia de TEDESCO et al. (1995) (Tabela 1).

A inoculação das plantas com o fungo Glomus clarum foi realizada com a adição de 5 gramas de inóculo por vaso. Este inóculo consistiu em substrato contendo solo rizosférico e raízes de aveia (Avena sativa L.) e foi adicionado na porção mediana do vaso. Após, completou-se o volume do recipiente e efetuou-se a semeadura de 10 sementes de aveia branca por vaso. Uma semana após sua emergência, realizouse desbaste das plantas, deixando-se 6 plântulas vaso-1. Quarenta e três dias após a semeadura, foram realizadas as avaliações de área foliar e matéria seca da parte aérea e de raiz, sendo as medidas de área foliar realizadas em um medidor de superfície foliar, de marca Li-Cor, modelo LI - (3000).

Para a quantificação da matéria seca da parte aérea e das raízes, o material foi primeiramente lavado com água destilada e, após, acondicionado em sacos de papel e levado à estufa, onde se procedeu a sua secagem, a $60^{\circ} \mathrm{C}$, até peso constante. Após esse período, procedeu-se à pesagem em balança de precisão.

A análise da qualidade de raízes foi efetuada visualmente, após sua lavagem e antes da secagem delas em estufa. Foram atribuídas notas de 0 a 9 . Nessa escala, 0 = péssimo desenvolvimento de raízes e de radicelas, $3=$ desenvolvimento ruim e pouca presença de radicelas; 5 = regular desenvolvimento e presença de radicelas; 7 = bom desenvolvimento e boa presença de radicelas; $9=$ excelente desenvolvimento e presença de radicelas.

Para determinação da colonização radicular por FMA, utilizou-se a técnica de coloração de raízes citada por COLOZZI-FILHO \& BALOTA (1994). Analisou-se a presença de hifas, vesículas e arbúsculos e a intensidade de colonização por FMA, segundo a técnica de contagem descrita por NEMEC (1992). Analisaram-se 20 segmentos de raízes por parcela, através da observação em microscópio óptico (250400 vezes).

Para a interpretação dos resultados, foi realizada análise de regressão polinomial das variáveis estudadas em relação ao percentual de volume de turfa do substrato, utilizando o software R (2012).

\section{RESULTADOS E DISCUSSÃO}

Observa-se que o TTSS foi mais elevado na turfa, decrescendo com o aumento da areia na mistura (Tabela 1). No entanto, esses teores de sais são considerados baixos para a maioria dos cultivos (KÄMPF, 2000). 
Os teores de CO foram da ordem de $0 \%$; $2,4 \% ; 8 \% ; 14 \%$ e $32 \%$, nos T1, T2, T3, T4, e T5, respectivamente, (Tabela 1). Esses teores de CO dos substratos utilizados, à exceção do T5, podem ser considerados baixos, levando em consideração que VERDONK et al. (1981) e PENNIGSFELD (1983) estabeleceram 50\% como valor mínimo de matéria orgânica para substratos hortícolas. Se considerar-se que 50 a $60 \%$ da matéria orgânica é constituída por carbono, conclui-se que um substrato hortícola deve ter no mínimo $25 \%$ de carbono orgânico (CO).

Conforme a tabela 1 , os substratos apresentaram valores de densidade úmida (DU) e densidade seca (DS) crescentes, proporcionalmente à adição de areia à mistura. BUNT (1973) cita como ideal uma DS para substrato hortícola entre 400 e $500 \mathrm{~kg} \mathrm{~m}^{-3}$ para recipientes de $350 \mathrm{ml}$. Dessa forma, apenas T4, com uma DS de $525,9 \mathrm{~kg} \mathrm{~m}^{-3}$, teria uma densidade adequada. Os tratamentos T1, T2 e T3 apresentam valores muito acima do ideal, o que diminui a porosidade total (PT), gerando menor espaço de aeração (EA) e menor disponibilidade de água às plantas, dificultando o crescimento das raízes. O tratamento T5 apresentou densidade muito baixa, o que pode prejudicar a sustentação da planta, quando utilizado como único meio de cultivo.

A PT considerada ideal para substratos hortícolas, segundo DE BOODT \& VERDONCK (1972), é de $0,85 \mathrm{~m}^{3} \mathrm{~m}^{-3}$. O substrato T5 foi o que esteve mais próximo desse valor, com $0,88 \mathrm{~m}^{3} \mathrm{~m}^{-3} \mathrm{de} \mathrm{PT}$. Os valores de PT cresceram desde T1 até o substrato T5, identificando que a adição de um material orgânico (turfa vermelha) melhorou a PT do substrato. Com o aumento da porosidade total do substrato-inóculo, há uma diminuição na densidade dele, o que facilita a sua comercialização e transporte.

Os substratos utilizados apresentaram valores de EA inferiores a $0,3 \mathrm{~m}^{3} \mathrm{~m}^{-3}$ (Tabela 1), nível considerado ideal por PENNINGSFELD (1983), sendo o substrato utilizado em T5 o que mais se aproximou desse índice, com $0,21 \mathrm{~m}^{3} \mathrm{~m}^{-3}$ e o T1, o menor valor, com $0,07 \mathrm{~m}^{3} \mathrm{~m}^{-3}$.

Nenhum dos substratos utilizados atingiu a faixa ideal de volume de água disponível (AD) $\left(24-40 \mathrm{~m}^{3}\right.$ $\mathrm{m}^{-3}$ ) e de volume de água facilmente disponível (AFD) $\left(20-30 \mathrm{~m}^{3} \mathrm{~m}^{-3}\right)$, ambas estabelecidas por DE BOOT \& VERDONCK (1972). No entanto, substratos contendo misturas de areia e turfa vermelha (T2, T3 e T4) apresentaram valores um pouco mais elevados do que substratos contendo somente um dos componentes (T1 e T5) (Tabela 1).

O T5 apresentou valor mais alto de AT em relação ao $\mathrm{T} 1\left(0,05 \mathrm{~m}^{3} \mathrm{~m}^{-3}\right.$ no $\mathrm{T}$, contra $0,001 \mathrm{~m}^{3} \mathrm{~m}^{-3}$ no T1)
(Tabela 1). O valor de AT do T5 foi idêntico ao estipulado por CATTIVELLO $(1991)\left(0,05 \mathrm{~m}^{3} \mathrm{~m}^{-3}\right)$ como ideal.

Quanto ao volume de AR-100, cujo padrão ideal fica na faixa de $0,25-0,30 \mathrm{~m}^{3} \mathrm{~m}^{-3}$ (VERDONCK \& GABRIELS, 1988), somente T4 situou-se dentro do ideal. Sendo que, enquanto T5 apresenta excesso de AR-100 $\left(0,37 \mathrm{~m}^{3} \mathrm{~m}^{-3}\right)$, podendo causar encharcamento excessivo às raízes; $\mathrm{T} 1, \mathrm{~T} 2 \mathrm{e} \mathrm{T} 3$ situaram-se abaixo da faixa ideal para AR-100, exigindo irrigação constante ao serem utilizados como substrato para o cultivo de plantas em recipientes.

A umidade do meio interfere na germinação de esporos de FMA, na colonização de raízes e esporulação dos fungos, havendo um efeito negativo em condições de excesso de umidade. Isso porque, nessa situação, há redução na aeração do solo e, sendo os FMA aeróbios, a redução de $\mathrm{O}_{2}$ é prejudicial (SILVEIRA, 1992).

Ao analisar-se a capacidade de retenção de água das misturas (Tabela 1), observa-se que, quanto maior a percentagem de $\mathrm{CO}$ do substrato, situação verificada em T5, maior o volume de água retido. Essa situação verifica-se em função de que a adição de uma fonte de matéria orgânica ao substrato diminui a percentagem de macroporos, em relação aos meso e microporos, aumentando, por consequência, a retenção de água. Através somente da análise das características físicas do substrato e comparando com a curva de um substrato ideal descrita por KÄMPF (2000), verifica-se que o substrato que mais se aproxima do ideal é um substrato intermediário entre T4 e T5.

Na tabela 1, verifica-se que os teores de macro e micronutrientes no substrato aumentaram proporcionalmente com o incremento de $\mathrm{CO}$, com exceção de Zn, Cu e B. Apesar de não se ter encontrado correlação significativa entre os teores de nutrientes e a colonização das plantas por FMA, não se descarta sua influência nos resultados obtidos.

Observa-se que, para a variável matéria seca das raízes, não se encontrou significância dos desvios de regressão, mas a área foliar, a matéria seca da parte aérea e a qualidade das raízes de aveia aumentaram linearmente com o incremento de $\mathrm{CO}$ do substrato. Ainda, os coeficientes de determinação indicam que a matéria orgânica explica $74 \%$ da variação na área foliar, $80 \%$ da massa seca da parte aérea e $86 \%$ da qualidade das raízes (Figura 1). As raízes de plantas cultivadas em meio com mais areia cresceram mais em comprimento, emitindo menos raízes secundárias e terciárias. Nos substratos com maior teor de $\mathrm{CO}$, ocorreu o oposto.

O maior desenvolvimento da parte aérea das plantas e da qualidade das raízes, em função do 
acréscimo da matéria orgânica do substrato, deve-se, sabidamente, ao maior aporte de $\mathrm{N}$ que esse tipo de material proporciona, bem como por apresentar níveis mais elevados de P, K, Ca e Mg (Tabela 1).

A presença de hifas, arbúsculos e vesículas quando analisadas de forma isolada não são suficientes para explicar o padrão de colonização do fungo de acordo com o volume de turfa vermelha no substrato (Figura 2), pois arbúsculos e vesículas apresentam vida média de 20 a 30 dias e, no momento da avaliação, algumas plantas podem apresentar um número acentuado dessas estruturas em senescência. No entanto, o somatório dessas três variáveis, dado pela quantidade de raízes colonizadas, explica bem o comportamento de Glomus clarum em função da presença de turfa vermelha no substrato. Dessa forma, observa-se que a percentagem de colonização apresentou comportamento quadrático negativo em relação à turfa vermelha no substrato, ocorrendo um incremento na colonização até o nível de 32,5\% de turfa, a partir do qual ocorreu uma queda gradual nela, à medida que aumentou a proporção desse componente do substrato (Figura 2).

A comparação das diferentes curvas de regressões das características físicas do substrato, em função da sua quantidade de turfa vermelha, indica que a água facilmente disponível apresenta curva de regressão com padrão semelhante à curva de regressão da colonização de Glomus clarum em função dos níveis de turfa do substrato. Essa semelhança pode ser observada na figura 2 , notando-se, inclusive, o mesmo ponto máximo nas duas curvas, de 32,5\%.

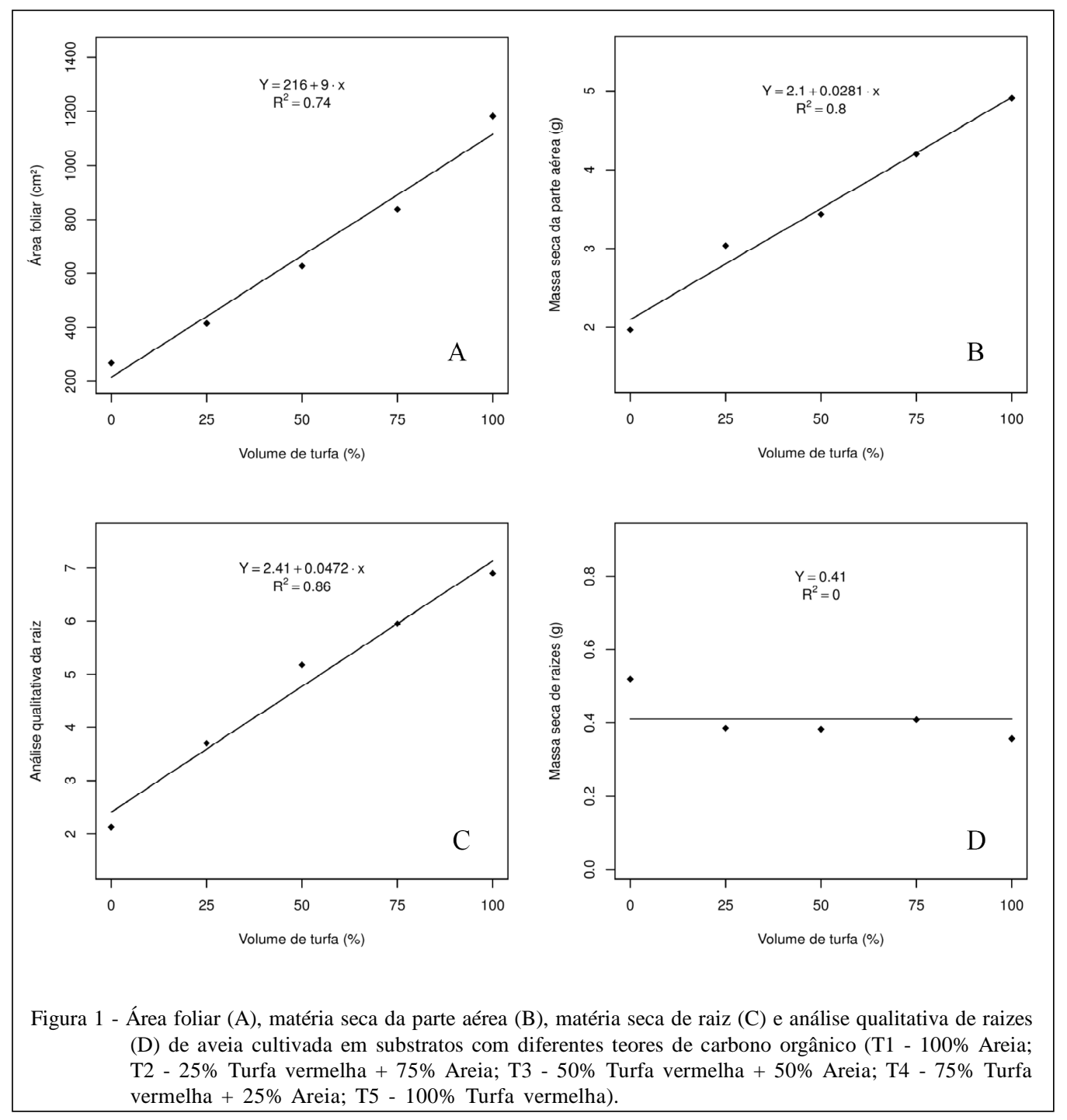

Ciência Rural, v.43, n.3, mar, 2013. 


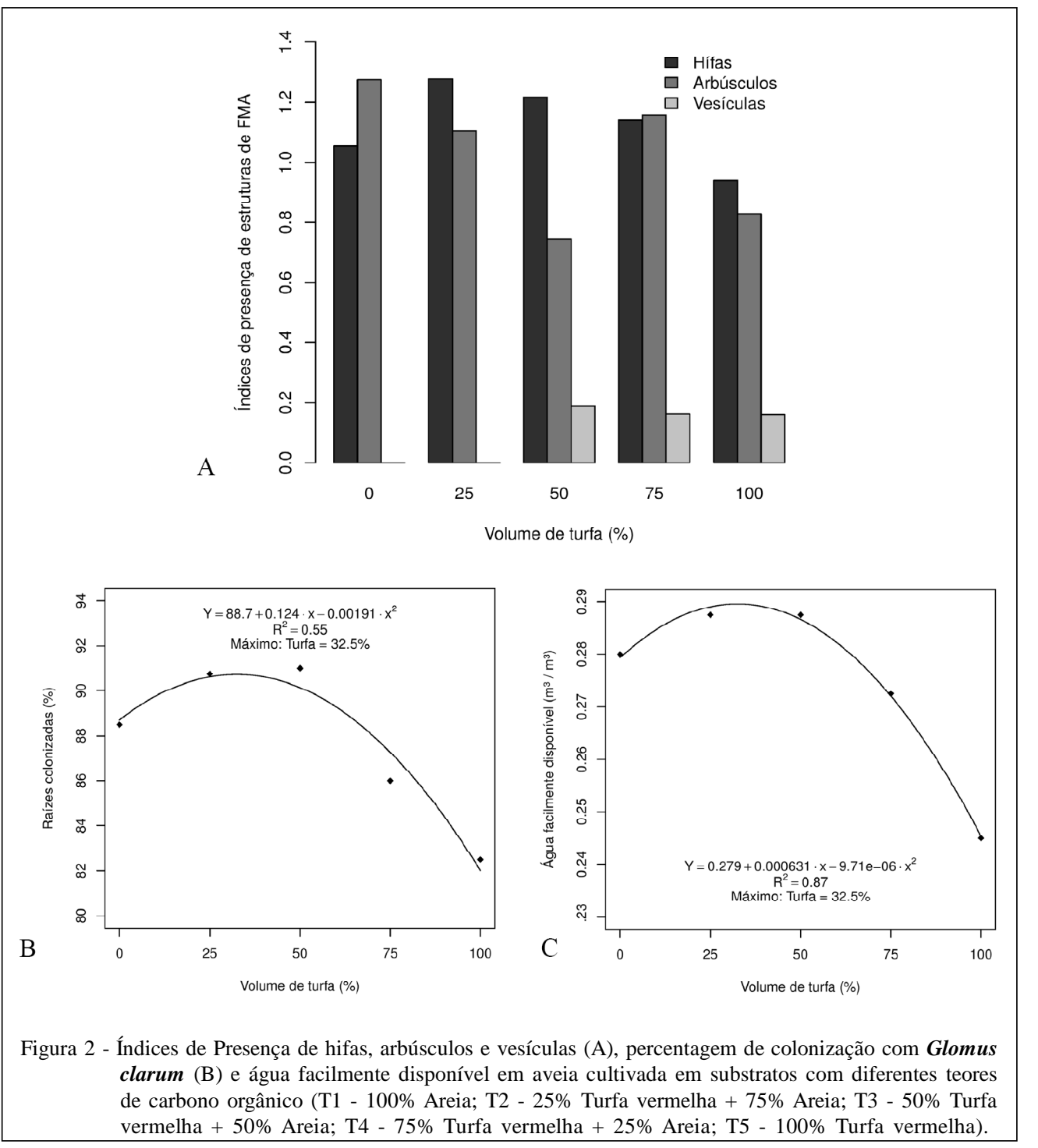

O fato de a colonização das raízes por FMA atingir um pico e depois decrescer, em função do incremento dos níveis de turfa vermelha no substrato, também foi observado no estudo de TRINDADE et. al. (2000). No entanto, MATOS et al. (2002) constataram que a adição de matéria orgânica ao substrato, independentemente da quantidade adicionada, acarretou diminuição acentuada na colonização das raízes da bananeira. Essas diferenças de resultados indicam a possibilidade de haver interação entre espécie de planta, espécie de FMA e percentagem de matéria orgância do substrato. Neste trabalho, as análises denotam que a colonização melhora em uma mistura da turfa vermelha e areia e que, proporções iguais ou menores de turfa vermelha são mais indicados para se obter melhores colonizações por Glomus clarum.
Os atributos físico-químicos dos substratos devem apresentar características tais que associem crescimento satisfatório da planta a uma satisfatória multiplicação dos FMAs. Os resultados obtidos neste trabalho demonstram que o aumento de desenvolvimento vegetativo da aveia branca (Figura 1) é acompanhado pelo aumento na colonização micorrízica das sua raízes (Figura 2) até o nível de incremento de turfa vermelha no substrato de $32,5 \%$, a partir do qual verificam-se reduções nos níveis de colonização das raízes por Glomus clarum .

\section{CONCLUSÃO}

O desenvolvimento vegetativo da parte aérea e a qualidade de raízes em aveia respondem 
linearmente a níveis de inclusão de turfa vermelha até o uso de $100 \%$ desta, mas a percentagem de colonização micorrízica da aveia por Glomus clarum responde de forma quadrática aos níveis de inclusão de turfa vermelha, sendo mais eficiente para produção de substrato-inóculo deste fungo o uso em torno de $32,5 \%$ de turfa vermelha.

\section{REFERÊNCIAS}

AZCÓN, R. et al. Significance of treated agrowaste residue and autochthonous inoculates (Arbuscular mycorrhizal fungi and Bacillus cereus) on bacterial community structure and phytoextraction to remediate soils contaminated with heavy metals. Chemosphere, Oxford, v.75, n.3, p.327-334, 2009. Disponível em: <http://www.sciencedirect.com/science/article/ pii/S0045653508015294>. Acesso em: 26 set. 2012. doi: http://dx.doi.org/10.1016/j.chemosphere.2008.12.029.

BELLÉ, S. Uso da turfa "Lagoa dos Patos" (Viamão/RS) como substrato hortícola. 1990. 143f. Dissertação (Mestrado em Fitotecnia) - Programa de Pós-graduação em Agronomia. Universidade Federal do Rio Grande do Sul, RS.

BUNT, A.C. Some physical and chemical charecteristicsof loamless pot-plant substrates and their relation to plant growth. Plant and Soil, The Hague, v.38, p.1954-1965, 1973. Disponível em: <http:/ /www.actahort.org/members/showpdf?session=5060>. Acesso em: 26 set. 2012.

COLOZZI-FILHO, A.; BALOTA, E.L. Micorrizas arbusculares. In: HUNGRIA, M.; ARAUJO, R.S. (Eds.). Manual de métodos empregados em microbiologia agrícola. Brasília: EMBRAPA, 1994. p.383-418.

De BOODT, M.; VERDONCK, O. The physical properties of the substrates in horticulture. Acta Horticulturae. Wageningen, n.26, p.37-44, 1972. Disponível em: <http:// www.actahort.org/members/showpdf?session $=10572>$. Acesso em: 26 set. 2012.

HOFFMANN, G. Verbindliche Methoden zur Untersuchung von tks und gärtnerischen Erden. Mitteilungen der VDLUFA, Herft, v.6, p.129-153, 1970.

KÄMPF, A.N. (Coord.). Produção comercial de plantas ornamentais. Guaíba: Agropecuária, 2000. 254p.

MATOS, R.M.B. et al. Micorriza arbuscular e matéria orgânica na aclimatização de mudas de bananeira, cultivar 'Nanicão'. Bragantia, Campinas, v.61, n.3, p.277-283, 2002. Disponível em: <http:// www.scielo.br/scielo.php?script $=$ sci_arttext \&pid $=$ S000687052002000300009>. Acesso em: 26 set. 2012. doi: http:// dxdoi.org.ez103.periodicos.capes.gov.br/10.1590/S000687052002000300009 .

MINHONI, M.T.A. et al. Efeitos da interação de fosfato de rocha, matéria orgância e fungo micorrízico no crescimento e na absorção de nutrientes pela soja. Revista Brasileira de Ciência do Solo, Viçosa, v.17, p.165-171, 1993.

NEMEC, S. Glomus intraradix effects on citrus roostock seedling growth in various potting media. Journal of Agricultural Science, Cambrige, v.118, p.315-323, 1992.
NUNES, M.S. Fungos micorrízicos arbusculares em portaenxertos de citros. 2004. 79f. Dissertação (Mestrado em Fitotecnia) - Curso de Pós-graduação em Ciências Agrárias, Universidade Federal da Bahia, Cruz das Almas, Ba.

PENNINGSFELD, F. Kulturusubstrate fur den gartenbau, besonders in Deutschland: ein kritischer Jberblick. Plant and Soil, The Hague, v.75, p.269-281, 1983.

R DEVELOPMENT CORE TEAM. R: a language and environment for statistical computing. Vienna, Austria: R Foundation for Statistical Computing. 2012. ISBN 3-90005107-0. Disponível em: 〈http://www.R-project.org/>. Acesso em: 28 set. 2012

RÖBER, R.; SCHALLER, K. Pflanzenernährung im gartenbau. Stuttgart: Ulmer, 1985. 352p.

SCHUMACHER, B.A. Methods for the determination of total organic carbon (toc) in soils and sediments. Las Vegas: US. Environmental Protection Agency, 2002. 23p.

SILVEIRA, A.P.D. Micorrizas. In: CARDOSO, E.J.B.N. et al. Microbiologia do solo. Campinas: S.B.C.S., 1992. p.257-282.

TEDESCO, M.J. et al. Análises de solos, plantas e outros materiais. Porto Alegre: Departamento de Solos da UFRGS, 1995. 215p. (Boletim Técnico de Solos, 5).

TRISTÃO, F.S.M. et al. Fungos micorrízicos arbusculares na formação de mudas de cafeeiro, em substratos orgânicos comerciais. Bragantia, Campinas, v.65, n.4, p. 649-658, 2006. Disponível em: <http://www.scielo.br.ez103.periodicos.capes.gov.br/pdf/brag/ v65n4/16.pdf>. Acesso em: 26 set. 2012. doi: http:// dx.doi.org.ez103.periodicos.capes.gov.br/10.1590/S000687052006000400016 .

TRINDADE, A.V. et al. Uso de esterco no desenvolvimento de mudas de mamoeiro colonizadas com fungos micorrízicos. Pesquisa Agropecuária Brasileira, Brasília, v.35, n.7, p.1389-1394, 2000. Disponível em: <http://www.scielo.br.ez103.periodicos.capes.gov.br/ pdf/pab/v35n7/1389.pdf>. Acesso em: 26 set. 2012. doi: http:// dx.doi.org.ez103.periodicos.capes.gov.br/10.1590/S0100204X2000000700013.

VERDONCK, O.; GABRIELS, R. Substrate requirements for plants. Acta Horticulturae, Wageningen, v.221, p.19-23, 1988. Disponível em: <http://www.actahort.org/members/ showpdf?session=23956>. Acesso em: 26 set. 2012.

VERDONCK, O. et al. The influence of the substrate to plant growth. Acta Horticulturae, Wageningen, n.126, p.251-258, 1981. Disponível em: <http://www.actahort.org/members/ showpdf?session=31071>. Acesso em: 26 set. 2012.

ZAMBOLIM, L.M.A.; COSTA, L.M. Substratos para multiplicação de inóculo do fungo micorrízico vesículoarbuscular Glomus clarum. Fitopatologia Brasileira, Brasília, v.17, n.1, p. 28-31, 1992.

ZEMKE, J.M. et al. Avaliação de substratos para inoculação micorrízica e aclimatização de dois porta-enxertos de videira micropropagados. Pesquisa Agropecuária Brasileira, Brasília, v.3, n.11, p.1309-1315, 2003. Disponível em: <http:/ /www.scielo.br.ez103.periodicos.capes.gov.br/pdf/pab/v38n11/ 18926.pdf>. Acesso em: 26 set. 2012. doi: http:// dx.doi.org.ez103.periodicos.capes.gov.br/10.1590/S0100204X2003001100009. 